\title{
Is there improvement in total factor productivity growth of the Indian pharmaceutical industry after TRIPS agreement? Evidence from Biennial Malmquist Index
}

\section{Dipyaman PAL}

Bethune College, Kolkata, West Bengal, India

Chandrima CHAKRABORTY

Vidyasagar University, Midnapore, WestBengal, India

Arpita GHOSE

Jadavpur University, Kolkata, India

\begin{abstract}
:
Aim: Indian Pharmaceutical Industry (IPI) has undergone a massive makeover-from a modest beginning of "process patents regime" in the seventies to a modern and WTO compatible regime under the Trade Related Intellectual Property Rights System (TRIPS) in 2005. This paper estimates Total Factor Productivity Growth (TFPG) of Indian Pharmaceutical Industry (IPI) using firm level data from 2000 to 2013.
\end{abstract}

Design / Research methods: We have used nonparametric approach of Data Envelopment Analysis (DEA) using Biennial Malmquist Index.

Conclusions / findings: The results of estimation suggest an increase in overall TFPG of IPI after TRIPS agreement and also those vertically integrated firms involved in both bulk drugs production and formulation activities are less productive compared to firms that are involved in production of only bulk drug or formulation activity.

Originality / value of the article: This paper examines whether productivity of IPI has increased after 2005 i.e. after the period of TRIPS, by estimating TFPG for two sub-periods, i.e., from 2000 to 2005 and 2006 to 2013.

Implications of the research: The decomposition of TFPG suggests that for overall period 2000-2013, scale changes are the most important factor causing the productivity changes and among the other two alternative sources of TFPG, efficiency change dominates over technical changes. For the sub-period 2006-2013, the improvement in the scale efficiency may push the firms to a higher TFPG, whereas for

Correspondence address: Dr. Dipyaman PAL, Department of Economics, Bethune College, Kolkata, West Bengal, India, E-mail: dipyaman.pal@gmail.com, chandrimaeco@gmail.com, arpitaju@gmail.com Received: 14.09.2017, Revised: 21.03.2018, Revised: 28.06.2018, Accepted: 28.06.2018 doi: http://dx.doi.org/10.29015/cerem.546 


\section{Dipyaman PAL, Chandrima CHAKRABORTY, Arpita GHOSE}

2000-2005 the better utilization of factors of production is the main driver of TFPG. A second stage panel regression suggests that R\&D expenditure, Marketing expenditure, Market size, Capital-Labour ratio, import intensity and export intensity have positive and significant influence on TFPG.

Key words: Total Factor Productivity Growth (TFPG), TRIPS, Indian Pharmaceutical Industry, Data Envelopment Analysis (DEA), Biennial Malmquist Index.

JEL: L65, C14, C33

\section{Introduction}

The growth of Indian Pharmaceutical industry (IPI) can broadly be classified into three phases. The first phase corresponds to the period 1900-1970 which signifies the dominance of multinationals (MNCs) (the market share being 68\% in 1970), which prevented the indigenous companies from producing new drugs, using the then existing patent law. Indigenous companies themselves were keener to process imported bulk drugs rather than developing the industry from basic stages. The size of the pharmaceutical industry was then very small as compared to its present status. The second phase corresponds to the period 1970-1990 witnessing the amendment of the Patent Act of 1911 which came into force in 1972. This change brought a renaissance to the IPI. After the changes in the patent law, large scale production of bulk drugs was started by the indigenous sector in the late 1970's, particularly in the 1980 's, as a result of which first, imports were replaced and secondly, consumption increased significantly leading to the unprecedented growth in formulation activity. Exports started increasing steadily. Till 1987-1988, imports were larger than exports except for a few years but with steady increase in exports the country has become a net exporter since 1988-1989. The net results of this are that MNCs lost their market domination. The market share of the MNC's declined from around $60 \%$ in the late 1970 's to around $40 \%$ in the early 1990 's. The favourable environment attracted the entry of a number of new firms. The third phase corresponds to the period after 1990s when significant changes occurred in Pharmaceutical sector with introduction of trade liberalization measures. During the period 1990s some significant changes occurred in the Pharmaceutical sector with the introduction of trade liberalization measures like amendment of FERA and MRTP Acts and delicensing of the drugs, reserved for production by the public sector. During this period Government of India signed the Trade Related Intellectual 
Property Rights System (TRIPS) agreement which came into existence with World Trade Organisation (WTO) established on 1 Jan1995 replacing The General Agreement on Tariff and Trade (GATT). The private sector growed rapidly along with increase in the competition among the domestic firms and foreign companies. As a result production of IPI increased manifoldalong with a sharp and steady increase in export. Net export as a percentage of total exports have also increased (Chaudhuri 2005). All those drugs which were reserved for the production by the public sector were delicenced in two stages. One immediate impact of this delicensing of the drugs was that production increased manifold besides increase in the competition among the domestic firms and foreign companies in 1990s. Both production and export have grown remarkably fast. There was sharp and steady increase of production and also of bulk drug production. As a result net exports as a percentage of exports have increased (Chaudhuri 2005).

Indian Pharmaceutical Industry (IPI) has undergone a massive makeover-from a modest beginning of "process patents regime" in the seventies to a modern and WTO compatible regime under the TRIPs Agreement in 2005.It ranked 3rd in volume and 14th in value in the global pharmaceutical market (Kalani, 2011). Since 2005, India has started full-fledged product patent regime in pharmaceuticals and are to develop new drugs themselves or to collaborate with the MNCs as manufacturing or marketing partners for the new drugs developed by the MNCs. (Chaudhuri 2005).

At this onset naturally the question arises that what happens to the total factor productivity growth (TFPG) in IPI especially after the TRIPs Agreement in 2005 ? The estimation of TFPG is thus essential, given the changed scenario of IPI in 2005. Following trade liberalization measures, improved performance of the industrial firms is now being called for an increase in productivity of a unit is now supposed to be a prerequisite for growth or even mere survival. In fact, government policies particularly after 2005, have gradually turned out to be less friendly to less productive firms. Such an analysis will definitely be helpful for framing appropriate policies for the development of IPI. The perusal of the literature on IPI signifies dearth in the studies dealing with these issues although some econometric studies are available on IPI (Lalitha 2002; Kumar 2001; Madanmohan 1997; Nagarajan, 


\section{Dipyaman PAL, Chandrima CHAKRABORTY, Arpita GHOSE}

Barthwal 1990; Singh 1989; Chandrasekhar, Purkayastha 1982). The present paper adds the literature in this direction.

This paper uses non-parametric approach of DEA to estimation of TFPG. Analysis of TFPG as well as finding out their determinants is of greater research interest as such studies may help policy makers and managers to devise and implement policies that may enhance TFPG in this dynamic and globally competitive industry. Studies on TFPG related to IPI are few in number like Saranga and Banker (2010), Pannu, Kumar and Farooquie (2010), Kamiike, Sato and Aggarwal (2012), Ghose and Chakraborty (2012) among others.

Sarangaand Banker (2010) studied the productivity change and factors behind from 1994 to 2003 using DEA. They found that few innovative firms have pushed the production frontier thereby increasing technical and productivity gains. They argued that higher technical and R\&D capabilities and wider new product portfolios of multinational-companies have contributed to positive technical and productivity changes. Whereas Pannu, Kumar and Farooquie (2010) using DEA analysed the impact of $R \& D$ and innovation on relative efficiency, productivity change and firm performance between 1998 and 2007. They found a positive impact of innovation and patents on productivity, market share, exports and ability to attract contract manufacturing. Study by Kamiike, Sato and Aggarwal (2012) using unit-level panel database analysed the impact of industry dynamics on TFPG across regions from 2000-01 to 2005-2006. They found that productivity growth is relatively higher in agglomerated region and effects of plant dynamics on productivity growth differ. Study by Ghose and Chakraborty (2012) estimated TFPG by estimating production function from 1973-1974 to 2003-2004, adjusted for stationarity after ADF-unit-root test. Translog form gave the better fit. Variation in TFPG is also explained.

Given this background, the objectives of the present paper are first of all to find out the TFPG of IPI by using Biennial Malmquist Index (BMI) of non-parametric method of Data Envelopment Analysis (DEA) for the period 2000 to 2013. This study also tried to find out the changed behavior of TFPG for IPI after 2005. After finding out the extent of TFPG, the second objective is to decompose TFPG into its different components: technical changes, efficiency changes and scale efficiency changes to check which component dominates over the other while finding out the 
major sources of TFPG. Thirdly, this paper tries to explain the factors behind the variation in TFPG of IPI.

The paper unfolds as follows: Section 2 describes the methodology and data sources. The results of estimation are present in section 3 . Section 4 concludes.

\section{Methodology and Data Source}

\subsection{Methodology of measuring Biennial Malmquist Index (BMI)}

In this paper we adopt the non-parametric (primal) approach to measure total factor productivity change. In the non-parametric approach, productivity index is used to measure productivity change.

Figure 1. Measurement and decomposition of productivity index

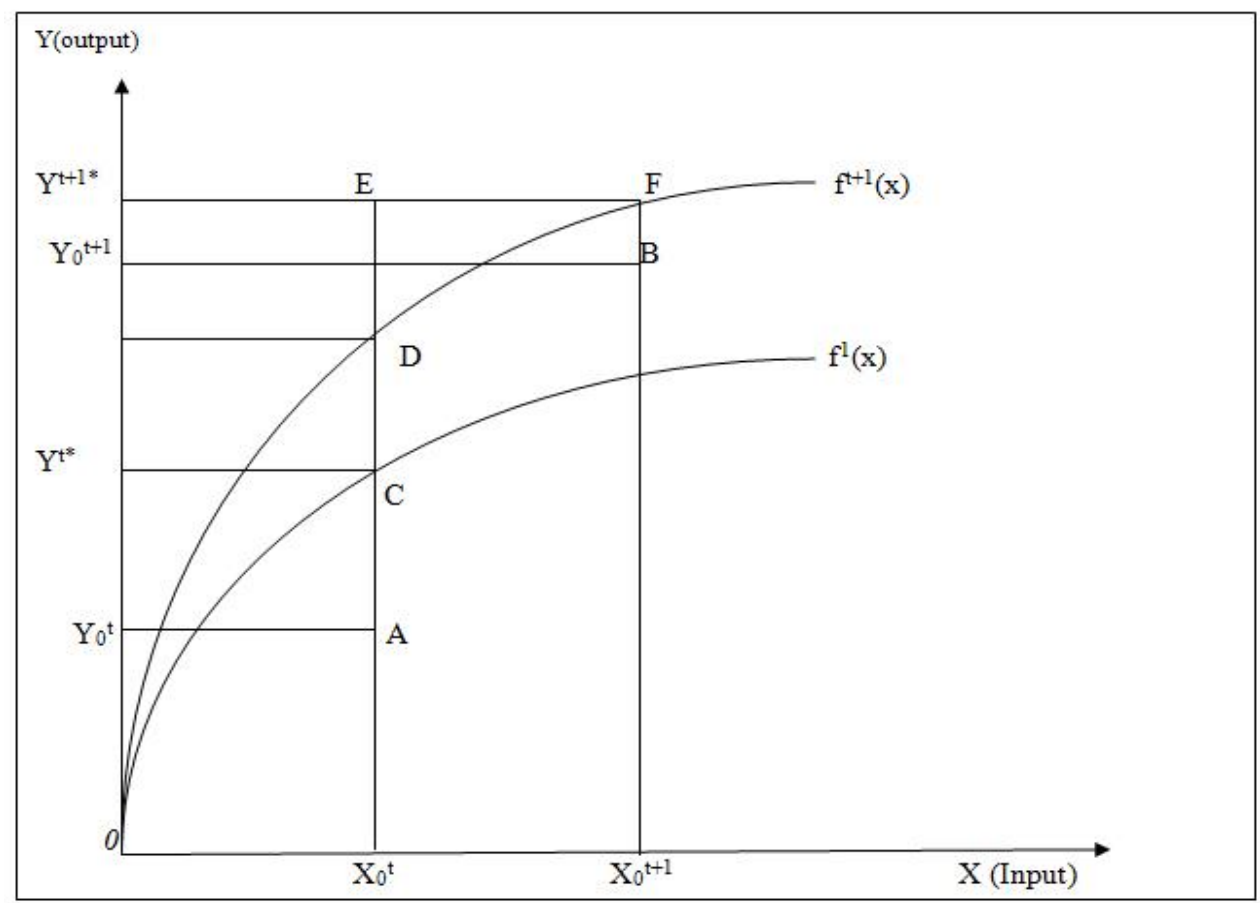

Source: Authors' own elaboration. 


\section{Dipyaman PAL, Chandrima CHAKRABORTY, Arpita GHOSE}

Figure 1 illustrates the measurement of productivity index and decomposition of it into above mentioned three components for a single input-single output case.

If in period $t$ a firm produces output $\mathrm{Y}_{0}{ }^{\mathrm{t}}\left(\right.$ Point $\mathrm{A}$ ) from input $\mathrm{X}_{0}{ }^{\mathrm{t}}$ its productivity is

$$
\pi_{t}=\frac{Y_{0}^{t}}{X_{n}^{t}}=\left(\frac{A x_{0}^{t}}{o x_{n}^{t}}\right)
$$

Similarly, in period $\mathrm{t}+1$, when output $Y_{\mathrm{n}}^{t+1}$ (Point $\mathrm{B}$ ) is produced from input $X_{0}^{t+1}$, the productivity is

$$
\pi_{t+1}=\frac{Y_{0}^{t+1}}{X_{0}^{t+1}}=\left(\frac{B X_{0}^{t+1}}{O X_{0}^{t+1}}\right) \ldots 2
$$

The productivity change in the period $t+1$, with period $t$ as the base is measured by

$$
\pi_{t+1] t}=\frac{\pi_{t+1}}{\pi_{t}}=\frac{\left(\frac{B X_{0}^{t+1}}{O X_{0}^{t+1}}\right)}{\left(\frac{A X_{0}^{t}}{O X_{0}^{t}}\right)}
$$

Now suppose that the production function is $Y^{t *}=f^{t}\left(X^{t}\right)$ in period $\mathrm{t}$ and $Y^{t+1 *}=f^{t+1}\left(X^{t+1}\right)$ in period $t+1$. Because each observed input-output bundle is by definition feasible in the relevant period, $f^{t}\left(X^{t}\right) \geq Y_{n}^{t}$ and $f^{t+1}\left(X^{t+1}\right) \geq Y_{n}^{t+1}$. Thus the productivity index, as defined in (3), can be rewritten and decomposed as

$$
\begin{aligned}
& \pi_{t+1 \mid t}=\frac{\pi_{t+1}}{\pi_{t}}=\frac{\left(\frac{B X_{0}^{t+1}}{O x_{0}^{t+1}}\right)}{\left(\frac{A x_{0}^{t}}{O X_{0}^{t}}\right)} \\
& =\frac{\left(\frac{B X_{0}^{t+1}}{F X_{0}^{t+1}}\right)}{\left(\frac{A x_{0}^{t}}{C x_{0}^{t}}\right)} X \frac{\left(\frac{F X_{0}^{t+1}}{O X_{0}^{t+1}}\right)}{\left(\frac{C X_{0}^{t}}{O x_{0}^{t}}\right)} \\
& =\frac{\left(\frac{B X_{0}^{t+1}}{F X_{0}^{t+1}}\right)}{\left(\frac{A X_{0}^{t}}{C X_{0}^{t}}\right)}\left(\frac{D X_{0}^{t}}{C X_{0}^{t}}\right) \frac{\left(\frac{F X_{0}^{t+1}}{O X_{0}^{t+1}}\right)}{\left(\frac{D X_{0}^{t}}{O X_{0}^{t}}\right)} \\
& =\left[\frac{\frac{Y_{0}^{t+1}}{f^{t+1}\left(X^{t+1}\right)}}{\frac{Y_{0}^{t}}{f^{t}\left(X^{t}\right)}}\right] X\left[\frac{f^{t+1}\left(X^{t}\right)}{f^{t}\left(X^{t}\right)}\right] X\left[\frac{\frac{f^{t+1}\left(X^{t+1}\right)}{X^{t+1}}}{\frac{f^{t+1}\left(X^{t}\right)}{X^{t}}}\right] \\
& =\text { TEC } X \text { TC } X \text { SEC }
\end{aligned}
$$


The first component in this expression (TEC) is the ratio of the technical efficiencies of the firm in two periods and captures the contribution of technical efficiency change over time. The second term (TC) shows how the maximum producible output from input $X_{0}^{t}$ changes between period $t$ and $t+1$ and captures the autonomous shift in the production function due to technical change. Finally the last term (SEC) identifies the returns to scale effect over time.

The Malmquist Productivity Index, introduced by Caves, Christensen, and Diewert (1982) and operationalized by Färe, Grosskopf, Lindgren and Roos (1992) (FGLR) to measure productivity change, is a normative measure based on a reference technology underlying observed input output data. Färe et al. (1992) (FGLR) decomposed the Malmquist Productivity Index (MPI) into technical change (TC) and technical efficiency change (TEC) considering the constant return to scale (CRS) frontier as the benchmark. However, assumption of global constant return to scale is not always a meaningful assumption about the underlying technology, so the FGLR decomposition is not particularly meaningful when CRS does not hold. In their paper Färe, Grosskopf, Norris, and Zhang (1994) re-modified and extended decomposition by considering variable returns to scale and isolate specific contributions of technical efficiency change (TEC), technical change (TC), and scale efficiency change (SEC) towards the overall productivity change. According to Ray and Desli (1997), this decomposition raises a problem of internal consistency because it uses CRS and variable returns to scale (VRS) within the same decomposition. They provide a modified decomposition by using the variable returns to scale frontier as a benchmark. In that decomposition, scale efficiency change is obtained by considering both the constant returns to scale technology and the variable returns to scale technology. However, when one estimate cross-period efficiency scores (which is measured by comparing actual output of a firm in period $t$ with the maximum producible output from period $t+1$ input set) under a VRS technology, it may result in linear programming infeasibilities for some observations.

In 2011, Pastor, Asmild and Lovell provides a new Malmquist Index which is known as the Biennial Malmquist Index (BMI) which used the same decomposition as provided by Ray and Desli but it solved the infeasibility problem associated with 


\section{Dipyaman PAL, Chandrima CHAKRABORTY, Arpita GHOSE}

the Ray-Desli decomposition of the Malmquist Index. Instead of using a contemporaneous production possibility frontier, they estimated the technical efficiency of a production unit with reference to a biennial production possibility frontier.

\subsection{Non Parametric Estimation of Productivity Index}

This study considers the non-parametric method of Data Envelopment Analysis (DEA) introduced by Charnes, Cooper and Rhodes (1978) and further generalized for variable returns to scale technology by Banker, Charnes and Cooper (1984) in order to measure and decompose the Malmquist index of total factor productivity.

The major advantage of using DEA is that, unlike in the parametric approach, there is no need to specify any explicit functional form for the production function (e.g., Cobb-Douglas or Translog) and mathematical programming techniques can be used to get point-wise estimates of the production function. In fact, DEA allows one to construct the production possibility set from observed input-output bundles on the basis of the following four assumptions:

a) All observed input-output combinations are feasible;

b) The production possibility set is convex;

c) Inputs are freely disposable; and

d) Outputs are freely disposable.

Now, consider an industry producing one output $y^{t}$ from one input $x^{t}$ in period $t$. The input output bundle $\left(x^{t}, y^{t}\right)$ is considered as feasible if the output $y^{t}$ can be produced from the input $x^{t}$. Let $\left(x_{j}^{t}, y_{j}^{t}\right)$ represent the input-output bundle of firm $j$; and suppose that input-output data are observed for $n$ firms. Then, based on the above assumptions, in period $t$, the production possibility set showing a variable returns to scale (VRS) technology is

$$
\boldsymbol{T}_{v}^{t}=\left\{(\boldsymbol{x}, \boldsymbol{y}): \boldsymbol{x} \geq \sum_{j=1}^{n} \lambda_{j} x_{j}^{t} ; y \leq \sum_{j=1}^{n} \lambda_{j} y_{j}^{t} ; \sum_{j=1}^{n} \lambda_{j}=1 ; \lambda_{j} \geq 0 ;(j=1,2,3, \ldots n)\right\}
$$

Under the constant returns to scale (CRS) assumption, if any $(x, y)$ is feasible, so is the bundle $(k x, k y)$ for any $k>0$. The production possibility set then becomes 


$$
\boldsymbol{T}_{c}^{t}=\left\{(\boldsymbol{x}, y) ; \boldsymbol{x} \geq \sum_{j=1}^{n} \lambda_{j} x_{j}^{t} ; y \leq \sum_{j=1}^{n} \lambda_{j} y_{j}^{t}, \lambda_{j} \geq 0 ;(j=1,2,3, \ldots n)\right\}
$$

One can measure the output-oriented technical efficiency $T E^{t}\left(x_{s}^{t}, y_{s}^{t}\right)$ of a firm $s$ in period $t$ by comparing its actual output $y_{s}^{t}$ with the maximum producible quantity from its observed input $x_{\sigma^{2}}^{t}$ Therefore, the output-oriented technical efficiency of firm $s$ in period $t$ is

$T E^{t}\left(x_{s}^{t}, y_{s}^{t}\right)=\frac{1}{\theta_{s}^{*} ;} \quad$ where $\theta_{s}^{*}=\max \quad \theta:\left(x_{s}^{t}, \theta y_{s}^{t}\right) \in T^{t}$ and $T^{t}$ is the period $\mathrm{t}$ production possibility set.

An alternative characterization of technical efficiency in terms of the Shephard Distance Function is $D^{t}\left(x_{s}^{t}, y_{s}^{t}\right)=\min \lambda:\left(x_{s}^{t}, \frac{1}{\lambda} y_{s}^{t}\right) \in T^{t}$. It can be seen that $\lambda=\frac{1}{\theta_{s}^{*}}$

Caves et al. (1982) defined the Malmquist Productivity Index as the ratio of the period $t$ and period $t+1$ output-oriented Shephard distance functions pertaining to a certain benchmark technology. Equivalently, the Malmquist Index of total factor productivity of the firm $s$ is

$$
\boldsymbol{M}_{c}\left(x_{s}^{t}, y_{s}^{t} ; x_{s}^{t+1}, y_{s}^{t+1}\right)=\left[\frac{T E_{c}^{t+1}\left(x_{s}^{t+1} y_{s}^{t+1}\right)}{T E_{s}^{t+1}\left(x_{N}^{t} y_{s}^{t}\right)} \frac{T E_{L}^{t}\left(x_{s}^{t+1} y_{s}^{t+1}\right)}{T E_{R}^{t}\left(x_{s}^{t} y_{s}^{t}\right)}\right]^{\frac{1}{2}}
$$

The standard non-parametric DEA model used to estimate the period $t$ outputoriented technical efficiency of a firm $s$, relative to contemporaneous CRS frontier is $\theta_{s}^{*}=\max \theta$

Subject to $\sum_{j=1}^{n} \lambda_{j} y_{j}^{t} \geq \theta y_{s}^{t}$;

$$
\begin{aligned}
& \sum_{j=1}^{n} \lambda_{j} x_{j}^{t} \leq x_{s}^{t} ; \\
& \lambda_{j} \geq 0 ;(j=1,2,3, \ldots n) ; \\
& \text { And } T E^{t}\left(x_{s}^{t}, y_{s}^{t}\right)=\frac{1}{\theta_{s}^{*}}
\end{aligned}
$$

By imposing the additional restriction $\sum_{j=1}^{n} \lambda_{j}=1$ in this DEA model, period $\mathrm{t}$ out-put oriented technical efficiency under VRS technology of a firm s can be estimated as $T E_{v}^{t}\left(x_{s}^{t}, y_{s}^{t}\right)$.

It has been already mentioned that the Biennial Malmquist Index introduced by Pastor, Asmild, and Lovell (2011) provides the same decomposition and avoids the 
infeasibility problem associated with the Ray-Desli decomposition of the Malmquist Index.

Instead of using a contemporaneous production possibility frontier, they estimated the technical efficiency of a production unit with reference to a biennial production possibility frontier. So in order to understand the Biennial Malmquist Index one has to first construct the Biennial Production Possibility Frontier.

Figure2. Simple graphical illustration of biennial production possibility frontier

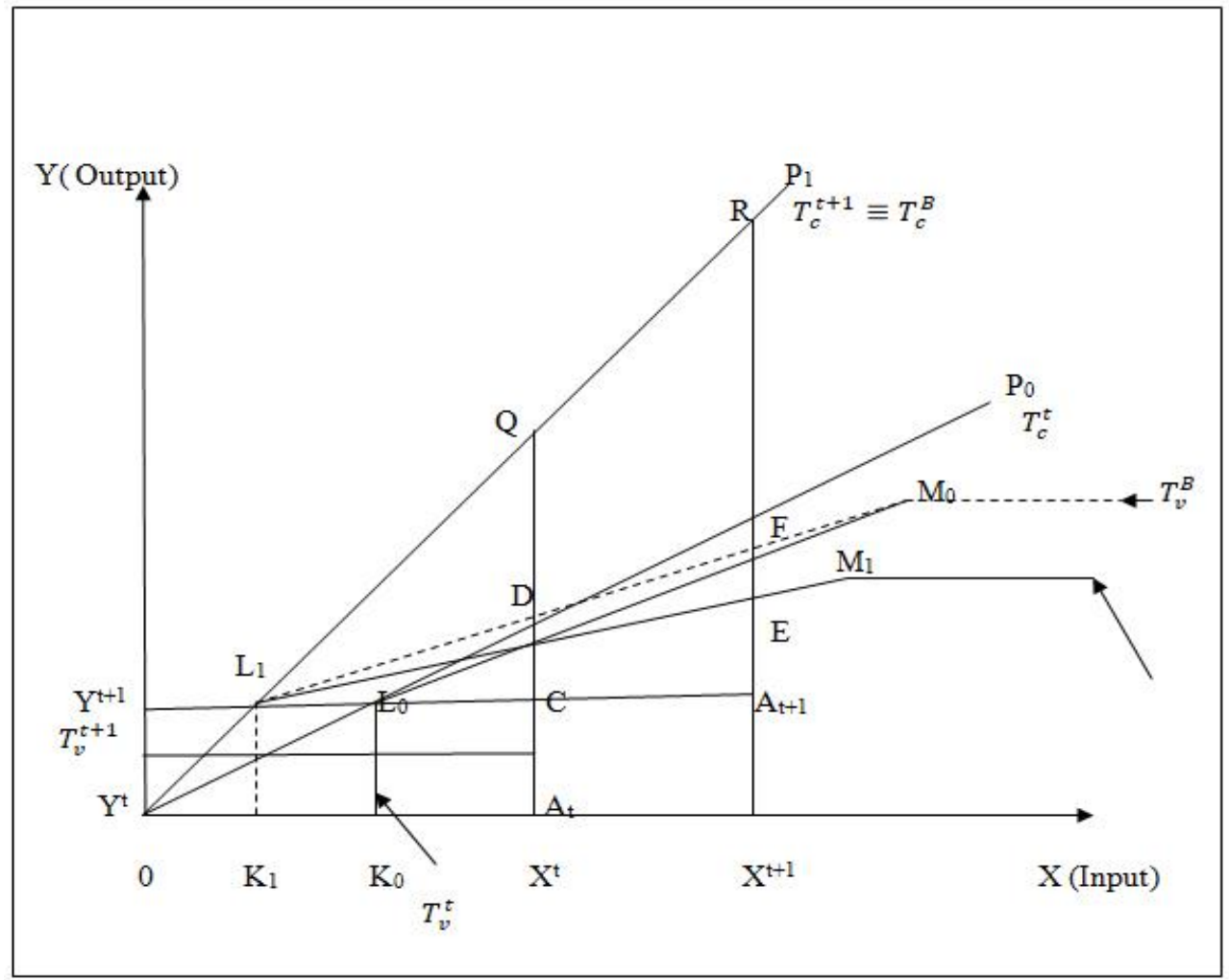

Source: Authors' own elaboration.

Figure 2 provides an illustration of the biennial production possibility frontier and measure of output-oriented technical efficiency with reference to it for a firm, producing a single output from a single input, observed in two time periods $t$ and $t+1$ (point $\mathrm{A}$ and $\mathrm{B}$ respectively). The VRS frontiers for period $t$ and $t+1$ are indicated by $\mathrm{K}_{0} \mathrm{~L}_{0} \mathrm{M}_{0^{-}}$extension and $K_{I} L_{I} M_{l^{-}}$extension respectively. The rays 
through origin $O P_{0}$ and $O P_{l}$ represent the CRS frontiers for period $t$ and period $t$ +1 respectively. The biennial VRS frontier is indicated by the broken line $K_{l} L_{1}$ $D F M_{0^{-}}$extension and the biennial CRS frontier in this case coincides with that of period $t+1$. Output-oriented technical efficiency of the firm with reference to CRS biennial frontier in period $t$ is

$$
T E_{c}^{B}\left(x^{t}, y^{t}\right)=\left(\frac{A_{t} X^{t}}{Q X^{t}}\right) \text { and that for period } \mathrm{t}+1 \text { is } T E_{c}^{B}\left(x^{t+1}, y^{t+1}\right)=\left(\frac{A_{t+1} X^{t+1}}{R X^{t+1}}\right) .
$$

Similarly with reference to the VRS biennial frontier, $T E_{v}^{B}\left(x^{t}, y^{t}\right)=\left(\frac{A_{t} X^{t}}{D X^{t}}\right)$ and $T E_{v}^{B}\left(X^{t+1}, y^{t+1}\right)=\left(\frac{A_{t+1} X^{t+1}}{F X^{t+1}}\right)$ show the levels of technical efficiency for the period $\mathrm{t}$ and $\mathrm{t}+1$ respectively. The reference technology set $T^{B}$ is defined as the convex hull of pooled data from both period $t$ and $t+1$.

Using the output-oriented technical efficiency scores with reference to a CRS biennial frontier, the Biennial Malmquist Productivity Index of the firm $s$ producing a single output from multiple inputs is measured as (Since the Biennial Malmquist Index of productivity uses the biennial CRS production possibility set, which includes the period $t$ and $t+l$ sets, one need not to calculate a "geometric mean" of two productivity indexes while measuring it)

$$
M_{c}^{B}\left(x_{s}^{t}, y_{s}^{t} ; x_{s}^{t+1}, y_{s}^{t+1}\right)=\frac{T E_{c}^{B}\left(x_{s}^{t+1}, y_{s}^{t+1}\right)}{T E_{R}^{B}\left(x_{s}^{t} y_{s}^{t}\right)} \quad \ldots 6
$$

The decomposition of this Biennial Malmquist productivity index is

$$
M_{c}^{B}\left(x_{s}^{t}, y_{s}^{t} ; x_{s}^{t+1}, y_{s}^{t+1}\right)=\operatorname{TECXTCXSEC} \quad \ldots 7
$$

Where

$$
\begin{aligned}
& \mathrm{TEC}=\frac{T E_{V}^{t+1}\left(x_{S}^{t+1} w_{S}^{t+1}\right)}{T E_{n}^{t}\left(x_{R}^{t} w_{N}^{t}\right)},
\end{aligned}
$$

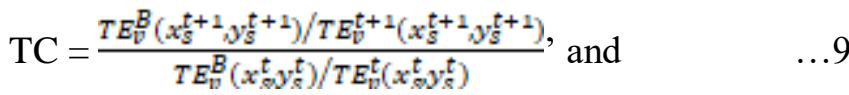

$$
\begin{aligned}
& \mathrm{SEC}=\frac{T E_{E}^{B}\left(x_{s}^{t+1}, y_{s}^{t+1}\right) / T E_{V}^{B}\left(x_{s}^{t+1} y_{s}^{t+1}\right)}{T E_{n}^{B}\left(x_{s}^{t} y_{k}^{t}\right) / T E_{n}^{B}\left(x_{\kappa}^{t} y_{s}^{t}\right)} \quad \ldots 10
\end{aligned}
$$

Now from figure 2 one can define Biennial Malmquist productivity index as

$$
M_{c}^{B}\left(x_{s}^{t}, y_{s}^{t} ; x_{s}^{t+1}, y_{s}^{t+1}\right)=\frac{\left(\frac{A_{t+1} X^{t+1}}{R X^{t+1}}\right)}{\left(\frac{A_{t} X^{t}}{Q X^{t}}\right)}
$$




\section{Dipyaman PAL, Chandrima CHAKRABORTY, Arpita GHOSE}

The decomposition of this Malmquist productivity index is

$$
\begin{aligned}
& M_{c}^{B}\left(X_{s}^{t}, y_{s}^{t} ; X_{s}^{t+1}, y_{s}^{t+1}\right) \\
& =\frac{\left(A_{t+1} X^{t+1} / E X^{t+1}\right)}{\left(A_{t} X^{t} / C X^{t}\right)} X \frac{\left(A_{t+1} X^{t+1} / F X^{t+1}\right) /\left(A_{t+1} X^{t+1} / E X^{t+1}\right)}{\left(A_{t} X^{t} / D X^{t}\right) /\left(A_{t} X^{t} / C X^{t}\right)} X \frac{\left(A_{t+1} X^{t+1} / R X^{t+1}\right) /\left(A_{t+1} X^{t+1} / F X^{t+1}\right)}{\left(A_{t} X^{t} / Q X^{t}\right) /\left(A_{t} X^{t} / D X^{t}\right)}
\end{aligned}
$$

Where

$$
\begin{aligned}
& \mathrm{TEC}=\frac{\left(A_{t+1} X^{t+1} / E X^{t+1}\right)}{\left(A_{t} X^{t} / C X^{t}\right)} \\
& \mathrm{TC}=\frac{\left(A_{t+1} X^{t+1} / F X^{t+1}\right) /\left(A_{t+1} X^{t+1} / E X^{t+1}\right)}{\left(A_{t} X^{t} / D X^{t}\right) /\left(A_{t} X^{t} / C X^{t}\right)} \\
& \mathrm{SEC}=\frac{\left(A_{t+1} X^{t+1} / R X^{t+1}\right) /\left(A_{t+1} X^{t+1} / F X^{t+1}\right)}{\left(A_{t} X^{t} / Q X^{t}\right) /\left(A_{t} X^{t} / D X^{t}\right)}
\end{aligned}
$$

The appropriate DEA model to estimate period $t$ output-oriented technical efficiency $T E_{c}^{B}\left(x_{s}^{t}, y_{s}^{t}\right)$ of firm $s$, with reference to a CRS biennial production possibility set is

$$
\varphi_{s}^{*}=\max \varphi
$$

Subject to $\sum_{k=t_{i} t+1} \sum_{j=1}^{n_{k}^{k}} \lambda_{j}^{k} y_{j}^{k} \geq \varphi y_{s}^{t} ;$

$$
\begin{aligned}
& \sum_{k=t_{i} t+1} \sum_{j=1}^{n_{k}} \lambda_{j}^{k} x_{j}^{k} \leq x_{s}^{t_{m}} \\
& \lambda_{j}^{k} \geq 0 ;
\end{aligned}
$$

Where $n_{k}$ is the number of observed firm in the period $\mathrm{k}$ and $T E_{c}^{B}\left(x_{s}^{t} y_{s}^{t}\right)=\frac{1}{\varphi_{s}^{*}}$

Period $\mathrm{t}$ output oriented technical efficiency $T E_{v}^{B}\left(x_{s}^{t}, y_{s}^{t}\right)$ of firm $s$, with reference to a VRS biennial production possibility set is

$\varphi_{s}^{*}=\max \varphi$

Subject to $\sum_{k=t_{i} t+1} \sum_{j=1}^{n_{k}^{k}} \lambda_{j}^{k} y_{j}^{k} \geq \varphi y_{s}^{t}$

$$
\begin{aligned}
& \sum_{k=t_{i}, t+1} \sum_{j=1}^{n_{k}} \lambda_{j}^{k} x_{j}^{k} \leq x_{s}^{t_{j}} \\
& \sum_{k=t_{i}, t+1} \sum_{j=1}^{n_{k}} \lambda_{j}^{k}=1 ; \\
& \lambda_{j}^{k} \geq 0 ;
\end{aligned}
$$

Where $n_{k}$ is the number of observed firm in the period $\mathrm{k}$ and $T E_{c}^{B}\left(x_{s v}^{t} y_{s}^{t}\right)=\frac{1}{\varphi_{s}^{*}}$ 


\subsection{Determinants of TFPG}

The variables used as possible determinants of TFPG are export intensity (E), import intensity (I), Market size (MS), R\&D expenditure (RD), marketing expenditure (M) and Capital-Labour ratio (K/L).

Export intensity (E): One of the important characteristics of IPI is that they reengineer the imported technology and then re-export the product. Export plays a very important role for the growth in the pharmaceutical sector. [Theoretical and empirical literature supporting positive role of exports Goldar et. al. (2004), Ray (2006)]. The findings of Indian studies are mixed and industry specific, even during post-reform period. IPI exports a lot (Chaudhuri 2005). There is a common opinion that international export enhances economic growth of involved firms (see Balassa 1988). Economic policies under export-led growth strategy have been widely supported on the argument that exposure to international market through export helps to increase growth of exporters. Similarly, advocates of endogenous growth theory believe that export plays a crucial role by improving productivity and hence growth through innovation (Grossman, Helpman 1991) and technology transfer (Barro, Sala-i-Martin 1995). Through participation in export, growth can occur as a result of many factors such as capital accumulation, adoption of new technologies, research and development, changes in the organization of firms, etc. Export intensity is defined by Export as a ratio to total sales

Import intensity (I): IPI also imports a lot of goods especially intermediate goods. The imported intermediary good is an important channel through which technological diffusion takes place (see Tybout 2000); this may affect productivity and growth favorably. Imports allow countries to take advantage of other countries technology embodied in imported inputs. Suffice here to mention theories of importled growth due to Grossman and Helpman (1991). The removal of quantitative restrictions on imports and lowering of customs duties in the post liberalization era of the Indian economy should have improved access of imported raw materials and capital goods. Imports of materials embodying latest technologies should foster productivity, efficiency and the growth of the firms. Goldar et al. (2004) and Mazumder et al. (2012) reported positive relation between efficiency and imports. Import intensity is defined by import as a ratio to total sales 


\section{Dipyaman PAL, Chandrima CHAKRABORTY, Arpita GHOSE}

Market size (MS): It can be argued that higher the Market Size (MS) less is the competition. MS captures the effect of market structure on TFPG. Some studies argued that a negative relation between MS and TFP growth may occur because as MS falls, competition increases which may lead to cost-consciousness and drive for technological advancement. Others may point out that the advantages of big size, secured market and expect a positive association between MS and TFPG because as MS rises, competition falls, larger units are becoming more productive may be due to the advantages of big size and secured market. The conclusion from the empirical literature also varies and does not provide us a single answer (Katz 1969; Kendrick 1973). MS is obtained for each firm considering the ratio of total sales of each firm to total sales of Pharmaceutical industry.

$\mathrm{R} \& \mathrm{D}$ Expenditure (RD): In recent years theoretical models related to endogenous growth give emphasis to that $R \& D$ expenditures of individual firms contribute to unremitting long run growth of an economy through their industrywide spillover effect (Grossman, Helpman 1990a, 1990b) because as individual firms invest in R\&D for private knowledge that enhances their productivity and profit. Private knowledge of individual firms then spills over to the rest of the industry and becomes social knowledge which acts as external effects in enhancing the productivity of the firms. With this positive spill-over effect of R\&D, a constant or decreasing returns to scale aggregate production function may exhibit increasing returns to scale and thus may lead to sustained long run growth (Raut, Srinivasan 1993). Again, Cohen and Levinthal (1989) among others pointed out that even as knowledge from private R\&D capital spills over to create social or public domain knowledge, a firm must invest in R\&D to obtain the technical capability needed to make use of the public domain knowledge to improve its productivity and efficiency. One explanation of this later view is that industry-wide knowledge will not contribute to productivity gains unless the firm invests in R\&D. The technological capabilities approach also pointed out that the firm level technological capabilities in developing countries are formed through slight innovations which include incremental modifications in the plants and machineries, efficiently using technologies, imitation, absorption and adaptation of imported technologies etc. These small modifications are largely generated by firms' in-house R\&D efforts and 
the development of human resources and skills, notably on job training (Lall 2000). Thus question can be raised to what extent increase in $\mathrm{R} \& \mathrm{D}$ helps to promote productivity in this IPI sector? The present article tests this hypothesis empirically, where $R \& D$ activity is measured by $R \& D$ expenditure which is defined by $R \& D$ expenditure as a ratio to total sales.

Marketing Expenditure (M): This variable is measured by Marketing Expenditure as a ratio to total sales and it also serves as a proxy for product differentiation. Sheth and Sisodia (2002) argued that low productivity is due to the descending of marketing efficiency. Their study point out that some changes are needed at the corporate level and the most fundamental one is that corporations should treat marketing as an investment rather than an expense. Kao et al. (2006) evaluates Technical and Allocative Efficiency in Marketing and explains the positive relation between return and marketing expenditure, which is defined as a kind of investment. The return can be in the form of increased sales, or customers, or some form of infrastructure that makes acquiring these items easier.

Degree of mechanization (K/L): Degree of mechanization is captured by Capital-labor ratio $(\mathrm{K} / \mathrm{L})$ which serves as a technological variable ${ }^{1}$. Generally, positive relationship between $\mathrm{K} / \mathrm{L}$ and TFP growth is expected with the argument that capital-intensive technology or sophisticated, advanced technology will facilitate productivity growth by encouraging learning by doing. Thus it is interesting to test the hypothesis that whether more the firm is capital intensive higher may be TFPG. Ray (1997) found a positive relationship between these two. Whereas Ahluwalia (1991) find negative association between these two variables and argued that the industries with higher capital-labour ratio were the heavy industries under the public sector which places constraints on the operation of these industries with it's adverse impact on productivity.

Dummy Variables for formulation $\left(\mathrm{D}_{\mathrm{F}}\right)$ and both formulation \& bulk drugs $\left(\mathrm{D}_{\mathrm{FB}}\right)$ : Some of the studies like Chaudhuri (2012) argued that Imports of high priced finished formulations are expanding rapidly with manufacturing investments lagging behind. The aggregate market share of the MNCs in the formulations market has gone up dramatically with the taking over of some Indian companies by the MNCs.

\footnotetext{
${ }^{1} \mathrm{~K} / \mathrm{L}$ is considered as determinant of TFP growth by Ray (1997) and Bandyopadhyay (2000).
} 


\section{Dipyaman PAL, Chandrima CHAKRABORTY, Arpita GHOSE}

Thus it is necessary to check whether vertically integrated firm involved in both bulk drugs production and formulation activities are less productive or not as compared to firms that produce only bulk drugs or the firms doing formulation. For finding out whether vertically merged firms are doing well in terms of TFPG compared to the firms not merged vertically, two dummy variables have been defined, one for firms engaged in formulation $\left(\mathrm{D}_{\mathrm{F}}\right)$ and another for firms producing both formulation \& bulk drugs $\left(\mathrm{D}_{\mathrm{FB}}\right)$ taking firms engaged in bulk drugs production as the reference category. So $\mathrm{D}_{\mathrm{F}}=1$, for firms engaged in formulation and 0 otherwise; similarly $\mathrm{D}_{\mathrm{FB}}=1$ for firms producing both formulation \& bulk drugs and 0 otherwise.

Time Dummy $\left(\mathrm{D}_{\mathrm{T}}\right)$ : Also time dummy variables $\mathrm{D}_{\mathrm{T}}$ is defined as $\mathrm{D}_{\mathrm{T}}=1$ for 2006 to 2013 and 0 otherwise to capture the effect of TRIPS on TFPG.

It is expected that firms which are incurring more RD can increase their TFPG by expanding their information set. Again by spending on $\mathrm{M}$ a firm can increase its market share. Hence sales increases and the firm may try to increase its production with more efficient technologies. Also K/L and TFPG may found to be positively linked which may imply that the industry perhaps is conducive for capital-intensive production process. MS has positive role on the TFPG which implies that an increase in market size will improve TFPG of IPI may be due to easier access of quality inputs and getting advantage of scale economies. It may be quite evident that units which are enjoying more export per unit of output are more productive than others as they are learning suitable measures to improve their productivity level. Also one may expect positively affect TFPG as one of the purposes of doing import in IPI is to carry out the re-export process.

For finding out the determinants of TFPG, a panel regression analysis has been done using a seemingly unrelated regression (SUR) framework where each regression was adjusted for contemporaneous correlation (across units) and cross section heteroscedasticity and test for better model-fixed/random with Hausman test is done. In this paper SUR framework has been considered because since we are considering export intensity (E), import intensity (I), R\&D expenditure (RD), marketing expenditure $(\mathrm{M})$ and Capital-Labour ratio $(\mathrm{K} / \mathrm{L})$ among the determinants of TFPG, it is quite possible that the for IPI, decision to undertake export intensity 
(E), import intensity (I), R\&D expenditure (RD), marketing expenditure (M) and Capital-Labour ratio $(\mathrm{K} / \mathrm{L})$ by one firm may influence the decision of the same by other firms and hence the error term explaining the TFPG of one firm may be correlated with the error explaining the TFPG for the others.

\subsection{The Data sources}

The present study uses CMIE Prowess data base and those firms are selected for which all the data of inputs and outputs and the determinants are positive. On the basis of this fact, 90 firms have been selected. The time period is 2000 to 2013 .

\section{Results of estimation}

\subsection{Results of TFPG}

The TFPG for each of the years and also each firms are estimated. The results are then summarized to generate the information regarding the changes of TFPG for each year. Such estimation results are presented in Table 1. To capture the effect of TRIPS this paper divides total sample period in to two sub-periods, i.e., from 2000 to 2005 and 2006 to 2013 and compare the estimated values of TFPG for these periods. These results are also presented in Table 1 .

From Table 1 it can be concluded that there has been an increased in the TFPG over the total sample period. Not only that values of TFPG increased in the second half, i.e. after TRIPS as compare to 2000 to 2005 . So, it can be concluded that an increase in overall TFPG of IPI after TRIPS agreement is evident.

\subsection{Results of Decomposition of TFPG}

The estimated results of TFPG are then decomposed into Efficiency Changes, Scale Efficiency Changes and Technical Changes following the formula 7 to 10. For each of the year, the overall changes in the decomposition of TFPG as well as changes over the period from 2000-2005 and 2006-2013 are estimated. 
Dipyaman PAL, Chandrima CHAKRABORTY, Arpita GHOSE

Table 1. Results of TFPG of IPI

\begin{tabular}{|l|l|l|l|l|}
\hline YEAR & TEC & TC & SEC & MI \\
\hline 2000 & 0.995147 & 1 & 1.002609 & 0.997743 \\
\hline 2001 & 1 & 1 & 1.014529 & 1.014529 \\
\hline 2002 & 1 & 1 & 0.998382 & 0.998382 \\
\hline 2003 & 1 & 1 & 1 & 1 \\
\hline 2004 & 1.097111 & 1.002249 & 0.989028 & 1.087514 \\
\hline 2005 & 1 & 1 & 1.000529 & 1.000529 \\
\hline $\begin{array}{l}\text { AVERAGE (2000 } \\
\text { TO 2005) }\end{array}$ & $\mathbf{1 . 0 1 5 3 7 6}$ & $\mathbf{1 . 0 0 0 3 7 5}$ & $\mathbf{1 . 0 0 0 8 4 6}$ & $\mathbf{1 . 0 1 6 4 5}$ \\
\hline $\mathbf{2 0 0 6}$ & 1.032924 & 1 & 1.040142 & 1.074387 \\
\hline $\mathbf{2 0 0 7}$ & 1 & 1 & 1.002688 & 1.002688 \\
\hline $\mathbf{2 0 0 8}$ & 1 & 1 & 1.071032 & 1.071032 \\
\hline $\mathbf{2 0 0 9}$ & 1 & 1 & 1.000456 & 1.000456 \\
\hline $\mathbf{2 0 1 0}$ & 1.0178 & 1.000506 & 1.020663 & 1.039357 \\
\hline $\mathbf{2 0 1 1}$ & 1 & 1 & 1.000697 & 1.000697 \\
\hline $\mathbf{2 0 1 2}$ & 1.005563 & 1.00018 & 1.008582 & 1.014375 \\
\hline $\mathbf{2 0 1 3}$ & 1.006945 & 1.000172 & 1.007028 & 1.014196 \\
\hline $\begin{array}{l}\text { AVERAGE (2006 } \\
\text { TO 2013) }\end{array}$ & $\mathbf{1 . 0 0 7 9 0 4}$ & $\mathbf{1 . 0 0 0 1 0 7}$ & $\mathbf{1 . 0 1 8 9 1 1}$ & $\mathbf{1 . 0 2 7 1 4 9}$ \\
\hline $\begin{array}{l}\text { OVER ALL } \\
\text { AVERAGE }\end{array}$ & $\mathbf{1 . 0 1 1 1 0 6}$ & $\mathbf{1 . 0 0 0 2 2 2}$ & $\mathbf{1 . 0 1 1 1 6 9}$ & $\mathbf{1 . 0 2 2 5 6 3}$ \\
\hline SOur Author 0 ( & & & & \\
\hline
\end{tabular}

Source: Authors' own elaboration.

All the results are presented in Table-1. Entries in column TEC show average annual changes in the level of technical efficiency over time, a value greater than unity for this component implies that, for that particular year IPI has experienced improvement in technical efficiency over the previous period. Similarly, an entry with value greater (less) than unity in column TC reflects technological progress (regress) over time. The change in scale efficiency over time is reported in column SEC, with a value exceeding one again signaling an improvement in scale efficiency. From the results of Table 1, it can be concluded that productivity growth is mostly driven by the change in the scale efficiency for the entire sample period. The second important factor behind the changes in TFPG is the change in the technical efficiency. The change in the technology has the lowest impact on the 
increase in the productivity. So it can be concluded that changes in the scale and better utilization of factors of production may pushed IPI to be on higher TFPG for the period 2000 to 2013.

Now if one consider for the period 2000 to 2005 it can be concluded that the change in the technical efficiency is major factor behind the increase in TFPG. Productivity growth is also driven by the change in the scale efficiency for this period. Again, change in the technology has the lowest impact on the increase in the productivity. For the period 2006 to 2013 productivity growth has increased mostly for the change in the scale efficiency followed by the change in the technical efficiency. The change in the technology has again the lowest impact on the increase in the productivity.

Thus in conclusion it can be said that scale changes are the most important factor causing the productivity changes for IPI. Among the two other alternative sources of TFPG, an efficiency change dominates over technical changes. Thus, in case of IPI, the improvement in the technical efficiency may push the firms to a higher TFPG for the period 2006-2013. In case of 2000-2005 the better utilization of factors of production is the main factor behind the improvement in TFPG.

\subsection{Results of Determinants of TFPG}

All the results of a second stage panel regression are presented in Table 2. The estimated model also reports Adjusted $\mathrm{R}^{2}$ which represents the overall fit of the model, which is based on the difference between residual sum of squares from the estimated model and the sum of square from a single constant only specification, not from a fixed effect only specification. High value of Adjusted $R^{2}$ shows that the fitted models are reasonably good.

From the results of estimation of growth equation it can be concluded that there exists an inverted U shape relationship between TFPG and export intensity, capitallabour ratio and market size implying that there exists a threshold limit beyond these variables may affect the TFPG in reverse way. The overall marginal effects of all the determinants are positive implying that on a whole these determinants may increase the TFPG. So, it can be concluded that Capital-Labour ratio, market size and export intensity have positive and significant influence on the TFPG. The positive linkage 
between Capital-Labour ratio and TFPG may imply that this industry perhaps is conducive for capital-intensive production process. The relation between export intensity and TFPG is obtained to be positive suggesting that those units which are enjoying more export per unit of output are more efficient than others. In IPI one of the purposes of doing import is to carry out the re-export process. The effect of import intensity on TFPG of IPI is positive and significant. Market size has positive role on the TFPG which may imply that big firms are grown faster than the large firm. The effect of R\&D expenditure and Marketing expenditure on TFPG is positive and statistically significant although these relationships are not linear in nature.

Table 2. Estimated results of Second Stage Panel Regression

\begin{tabular}{|c|c|c|c|c|}
\hline \multicolumn{2}{|c|}{ Dependent Variable: BMI } & \multirow[b]{2}{*}{ Std. Error } & \multirow[b]{2}{*}{ t-Statistic } & \multirow[b]{2}{*}{ Prob. } \\
\hline Variable & Coefficient & & & \\
\hline C & $4.4912 *$ & 0.6555 & 6.8518 & 0.0000 \\
\hline $\mathbf{E}$ & $0.1673 *$ & 0.0391 & 4.2783 & 0.0000 \\
\hline I & $0.0170 *$ & 0.0027 & 6.3775 & 0.0000 \\
\hline RD & $0.2654 *$ & 0.0603 & 4.4022 & 0.0000 \\
\hline M & $2.3586 *$ & 0.9084 & 2.5964 & 0.0096 \\
\hline KBYL & $0.1052 *$ & 0.0257 & 4.0977 & 0.0000 \\
\hline MS & $7.5635^{*}$ & 3.1272 & 2.4186 & 0.0053 \\
\hline E2 & $-0.0024 * *$ & 0.0012 & -1.9787 & 0.0481 \\
\hline KBYL*KBYL & $-0.0009 *$ & 0.0004 & -2.4087 & 0.0061 \\
\hline MS2 & -4.3360 & 2.8923 & -1.4992 & 0.1810 \\
\hline DF & $1.7439 *$ & 0.1711 & 10.1929 & 0.0000 \\
\hline DBOTH & $-1.0458 *$ & 0.4618 & -2.2645 & 0.0238 \\
\hline DT & $0.8552 *$ & 0.4149 & 2.0612 & 0.0396 \\
\hline Adjusted R-squared & 0.7515 & & & \\
\hline F-statistic & $56.088692 *$ & & & \\
\hline $\operatorname{Prob}(F-$-statistic) & 0 & & & \\
\hline
\end{tabular}


Table 3. Marginal effects

\begin{tabular}{|l|l|}
\hline $\mathbf{E}$ & 0.1362 \\
\hline $\mathbf{I}$ & 0.0170 \\
\hline RD & 0.2654 \\
\hline M & 2.3586 \\
\hline KBYL & 0.3157 \\
\hline MS & 7.2025 \\
\hline
\end{tabular}

Source: Authors' own elaboration.

The dummy for vertically integrated firms involved in both bulk drugs production and formulation activities is negative and significant whereas the dummy for firms involved in formulation activity is positive and significant implying that those vertically integrated firms involved in both bulk drugs production and formulation activities are less productive compared to firms that produces only bulk drug or are involved in formulation activity. The coefficient of time dummy is positive and statistically significant implying that for the period 2006-2013 TFPG has increased as compared to the period 2000-2005.

\section{Conclusion}

Indian Pharmaceutical Industry (IPI) is one of the few industries which has been affected in a major way due to Trade Related Intellectual Property Rights System (TRIPS) agreement as from the year 2005 the existing Process Patent regime gave way to the Product Patent regime although the process of establishing a new patent regime in India started since 1995. In such an environment it will be interesting to examine whether there has been any improvement in the productivity of IPI after 2005 i.e. after the period of TRIPS. So, the paper estimates Total Factor Productivity Growth (TFPG) of Indian Pharmaceutical Industry (IPI) using firm level data from 2000 to 2013. TFPG is estimated by nonparametric approach of Data Envelopment Analysis (DEA) using Biennial Malmquist Index. To capture the effect of TRIPS this paper divides total sample period in to two sub-periods, i.e., from 2000 to 2005 


\section{Dipyaman PAL, Chandrima CHAKRABORTY, Arpita GHOSE}

and 2006 to 2013. An increase in overall TFPG of IPI after TRIPS agreement is evident. The decomposition analysis of TFPG suggests that scale changes are the most important factor causing the productivity changes for IPI. Among the two other alternative sources of TFPG, an efficiency change dominates over technical changes. In case of IPI, the improvement in the scale efficiency may push the firms to a higher TFPG for the period 2006-2013. In case of 2000-2005 the better utilization of factors of production is the main factor behind the improvement in TFPG.

This study pointed out those vertically integrated firms involved in both bulk drugs production and formulation activities are less productive compared to firms that produces only bulk drug or are involved in formulation activity. Also, for the period 2006-2013 TFPG has increased as compare to the period 2000-2005.

A second stage panel regression suggests that the determinants $R \& D$ expenditure, Marketing expenditure, Market size, Capital-Labour ratio, import intensity and export intensity have positive and significant influence on the TFPG implying that an increase in either of these variables can boost up TFPG of Indian Pharmaceutical Industry.

Thus this result reveals that although the TRIPS agreement may push the TFPG of IPI in a higher level but also in order to encourage total factor productivity growth, any policy changes that will lead to increase in the export intensity, import intensity, Market size, $\mathrm{R} \& \mathrm{D}$ expenditure, marketing expenditure and Degree of mechanization should be emphasized.

\section{References}

Ahluwalia I.J. (1991), Productivity growth in Indian manufacturing, Oxford University Press, New Delhi.

Balassa B. (1988), Outward orientation, in: Handbook of development economics, Chenery H., Srinivasan T.N. (ed.), vol. 2, Elsevier, New York, pp. 1645-1689.

Bandyopadhyay S. (2000), Impact of efficiency indicators on the growth of productivity. A survey and empirical evidence from India, „Margin”, vol. 33 no. 1, pp. 84-98.

Banker R.D., Charnes A., Cooper W.W. (1984), Some models for estimating technical and scale efficiencies in Data Envelopment Analysis, „Management Science”, vol. 30 no. 9, pp. 1078-1092. 


\section{IS THERE IMPROVEMENT IN TOTAL FACTOR PRODUCTIVITY GROWTH ...}

Barro R.J., Sala-i-Martin X. (1995), Economic growth, McGraw-Hill, New York.

Caves D., Laurits W., Christensen R., Diewert W.E. (1982), The economic theory of index numbers and the measurement of input, output and productivity, „Econometrica”, vol. 50 no. 6, pp. 1393-1414.

Chandrasekhar C.P., Purkayastha P. (1982), Transfer pricing in the Indian drug industry. An estimate and it's implications, „Social Scientist”, vol. 10 no. 1, pp. 3-10.

Charnes A., Cooper W.W., Rhodes E.L. (1978), Measuring the efficiency of decision-making units, „European Journal of Operational Research”, vol. 2 no. 6, pp. 429-444.

Charnes A., Cooper W.W., Rhodes E.L. (1981), Evaluating program and managerial efficiency - an application of Data Envelopment Analysis to Program Follow Through, „Management Science”, vol. 27 no.6, pp. 668-697.

Chaudhuri S. (2005), The WTO and India's pharmaceuticals industry. Patent protections, TRIPS and developing countries, Oxford University Press, New Delhi.

Chaudhuri S. (2012), Multinationals and monopolies. Pharmaceutical industry in India after TRIPS, „Economic \& Political Weekly”, vol. 47 no. 12, pp. 46-54.

Cohen W.M., Levinthal D.A. (1989), Innovation and learning. Two faces of R\&D, „Economic Journal”, no. 99, pp. 569-596.

Färe R., Grosskopf S., Lindgren B., Roos P. (1992), Productivity changes in Swedish pharmacies 198089. A non-parametric Malmquist approach, „Journal of Productivity Analysis”, vol. 3 no. 1/2, pp. 85101.

Färe R., Grosskopf S., Norris M., Zhang P. (1994), Productivity growth, technical progress and efficiency changes in industrial countries, „American Economic Review”, vol. 84 no. 1, pp. 66-83.

Ghose A., Chakraborty C. (2012), Total factor productivity growth in pharmaceutical industry. A look using modern time series approach with Indian data, „The Journal Of Industrial Statistics”, vol. 1 no. 2, pp. $250-268$.

Goldar B., Ranganathan V.S., Banga R. (2004), Ownership and efficiency in engineering firms, 199091 to 1999-2000, „Economic and Political Weekly”, vol. 39 no. 5, pp. 441-447.

Grossman G., Helpman E. (1990a), Comparative advantage and long run growth, „American Economic Review”, vol. 80 no. 4, pp. 796-815.

Grossman G., Helpman E. (1990b), Trade, innovation and growth, ,American Economic Review”, vol. 80 no. 2 , pp. $86-91$.

Grossman G., Helpman E. (1991), Innovation and growth in the global economy, The MIT Press, Cambridge.

Kalani S. (2011), Emerging role of IT in Indian pharmaceutical industry and its implications for the education system, „Pharma Times”, vol. 43 no. 5, pp. 25-27. 


\section{Dipyaman PAL, Chandrima CHAKRABORTY, Arpita GHOSE}

Kamiike A., Sato T., Aggarwal A. (2012), Productivity dynamics in the Indian pharmaceutical industry. Evidences from plant-level panel data, „Science, Technology and Society”, vol. 17 no. 3.

Kao L.-J., Chiu Ch.-Ch., Gilbride T.J., Greg T.O., Allenby M. (2006), A direct approach to evaluating technical and allocative efficiency in marketing, Fisher College of Business, Ohio State University, www.stat.osu.edu/ amd/papers/Efficiency.pdf [08.09.2018].

Katz J.M. (1969), Production function, foreign investment and growth, North-Holland Publishing Company, Amsterdam.

Kendrick J.W. (1973), Post war productivity trends in the United States, 1947-1969, National Bureau of Economic Research, New York.

Kumar N. (2001), WTO regime, host country policies and global patterns of MNE activity. Recent quantitative studies and India's strategic response, „Economic and Political Weekly”, vol.36 no.1, pp 39-50.

Lalitha N. (2002), Indian pharmaceutical industry in WTO regime. A SWOT analysis, „Economic and Political Weekly", vol. 37 no. 34, pp. 3542-3555.

Lall S. (2000), Technological change and industrialization in the Asian newly industrializing economies, in: Technology, learning, and innovation. Experiences of newly industrializing economies, Kim L., Nelson R.R. (ed.), Cambridge University Press, Cambridge, pp. 13-68.

Madanmohan T.R. (1997), Exit strategies. Experience of Indian pharmaceutical firms, „Economic and Political Weekly", vol. 32 no.48, pp. 107-110.

Mazumder M., Rajeev M., Ray S.C. (2012), Sources of heterogeneity in the efficiency of Indian pharmaceutical firms, „Indian Economic Review”, vol. 47 no. 2, pp. 191-221.

Nagarajan M., Barthwal R.R. (1990), Profitability and structure. A firm level study of the Indian pharmaceutical industry, „Indian Economic Journal”, vol. 38 no. 2, pp. 70-81.

Pannu H.S., Kumar U.D., Farooquie J.A. (2010), Impact of innovation on the performance of Indian pharmaceutical industry using Data Envelopment Analysis, IIM Bangalore Research Paper no. 302.

Pastor J.T., Asmild M., Lovell C. (2011), The biennial Malmquist productivity change index, „SocioEconomic Planning Sciences", vol. 45 no. 1, pp. 10-15.

Raut L.K., Srinivasan T.N. (1993), Theories of economic growth, old and new, in: Capital investment and development, Basu K., Majumdar M., Mitra T. (ed.), Basil Blackwell, New York.

Ray S.C. (1997), Regional variation in productivity growth in Indian manufacturing. A nonparametric analysis, „Journal of Quantitative Economics”, vol. B no.1, pp. 73-94.

Ray S.C. (2006), The changing role of technological factors in explaining efficiency in Indian firms, „Journal of Developing Areas”, vol. 40 no. 1, pp. 127-140.

Ray S.C., Desli E. (1997), Productivity growth, technical progress, and efficiency change in industrialized countries. Comment, „The American Economic Review”, vol. 87 no. 5, pp. 1033-1039. 


\section{IS THERE IMPROVEMENT IN TOTAL FACTOR PRODUCTIVITY GROWTH ...}

Saranga H., Banker R.D. (2010), Productivity and technical changes in the Indian pharmaceutical industry, „Journal of the Operational Research Society”, vol. 61 no. 12, pp. 1777-1788.

Sheth J.N., Sisodia R.S. (2002), Marketing productivity. Issues and analysis, „Journal of Business Research", vol. 55 no. 5, pp. 349-362.

Singh N. (1989), Trade behaviour of firms. An empirical study of the size and foreign collaboration effects, „Indian Economic Review”, vol. 24 no. 1, pp. 45-65.

Tybout J.R. (2000), Manufacturing firms in developing countries. How well do they do and why? „Journal of Economic Literature”, vol. 38 no. 1, pp. 11-44. 